\title{
1 Peak aerobic capacity from incremental shuttle walk test in chronic kidney
}

\section{2 disease}

3

4 Soteris Xenophontos ${ }^{1}$, Thomas J. Wilkinson ${ }^{2}$, Douglas W. Gould ${ }^{1}$, Emma L. Watson ${ }^{1}$, João

5 L. Viana ${ }^{3}$, Alice C. Smith ${ }^{2}$

6

$7 \quad{ }^{1}$ Department of Infection Immunity and Inflammation, University of Leicester, Leicester,

8 United Kingdom

$9 \quad{ }^{2}$ Leicester Kidney Lifestyle Team, Department of Health Sciences, University of Leicester, 10 Leicester, United Kingdom,

$11{ }^{3}$ Research Center in Sports Sciences, Health Sciences and Human Development, CIDESD,

12 University Institute of Maia, ISMAI, Maia, Portugal

15 Corresponding author:

16 Professor Alice Smith, Leicester Kidney Lifestyle Team, Department of Health Sciences,

17 University of Leicester, LE1 7RH, and John Walls Renal Unit, University Hospitals of 18 Leicester, Leicester, United Kingdom, LE5 4PW.

19

20 Email : aa50@1eicester.ac.uk

21 Twitter : @leicskidney

22 


\section{Acknowledgements}

24 We would like to thank Amy Clarke, Barbara Vogt, Darren Churchward, Patrick Highton and

25 Charlotte Grantham, researchers at the Leicester Kidney Lifestyle Team, for collection of some

26 of the assessment outcome data.

27

$28 \quad$ Funding

29 This research was co-funded by the National Institute for Health Research (NIHR) Leicester

30 Biomedical Research Centre (BRC) and the Stoneygate Trust. The views expressed in this

31 publication are those of the author(s) and not necessarily those of the NHS, NIHR Leicester

32 BRC or Department of Health. At the time of writing this manuscript, E.L.W. was supported

33 by a Kidney Research UK Post-Doctoral Fellowship (PDF2-2015).

34

35 Authors' Contributions

36 S.X. and T.J.W. were responsible for generation and collection of data, performed data analysis

37 and interpretation, and drafted and approved the final version of the submitted manuscript.

38 A.C.S., E.L.W., and J.L.V. were involved in conception and study design and revised and approved the final version of the manuscript. D.W.G. was responsible for generation/collection of data and revised and approved the final version of the manuscript.

41

42 Conflict of Interest

43 None declared.

44 The results presented in this paper have not been published previously in whole or part, except in abstract 45 format. 


\section{Corresponding author biodata}

47

48 Professor Alice Smith has worked in kidney research since 1989. Over the last 15 years she 49 has built up the Leicester Kidney Lifestyle Team (LKLT), a 20-strong multidisciplinary 50 research team who aim to optimise the health and wellbeing of kidney patients through 51 improved lifestyle management. Her bench-to-bedside translational research programme 52 encompasses basic laboratory investigations of muscle metabolism and cardiovascular factors 53 in CKD and the impact of lifestyle factors; clinical trials of the feasibility, efficacy and 54 effectiveness of lifestyle interventions; evaluation of outcomes measures; qualitative research 55 of patient and stakeholder perspectives; and the design, development, testing and 56 implementation of behavioural interventions to encourage healthy lifestyle. All the research is 57 underpinned by extensive and genuine patient and public involvement and engagement. 58 
60

61

62

63

64

65

66

67

68

69

70

71

72

73

74

75

76

77

78

79

80

81

82

83

84

\section{9}

\section{Abstract}

Background: Assessment of cardiorespiratory fitness is an important outcome in chronic kidney disease (CKD). We aimed to develop a predictive equation to estimate peak oxygen uptake $\left(\mathrm{VO}_{2 \text { peak }}\right)$ and power output ( $\left.\mathrm{W}_{\text {Peak }}\right)$, as measured during a cardiopulmonary exercise test (CPET), from the distance walked (DW) during the incremental shuttle walk test (ISWT).

Methods: Thirty-six non-dialysis CKD patients (17 male, age $61 \pm 12$ years, eGFR $25 \pm 7$ ml.min ${ }^{-1} .1 .73 \mathrm{~m}^{-2}$, BMI $31 \pm 6 \mathrm{~kg} / \mathrm{m}^{2}$ ) carried out laboratory based CPET on a cycle ergometer and ISWT on two separate occasions.

Results: Linear regression revealed that DW/BMI was a significant predictor of $\mathrm{VO}_{2 \text { Peak }}(r=$ $0.78)\left(\mathrm{VO}_{2 \text { Peak }}\left(\mathrm{ml} \cdot \mathrm{min}^{-1} \cdot \mathrm{kg}^{-1}\right)=[0.5688 \mathrm{x}(\mathrm{DW} / \mathrm{BMI})(\mathrm{m})]+11.50\right)$. No difference $(p=0.66)$ between CPET VO 2 Peak $\left(19.9 \pm 5.5 \mathrm{ml} \cdot \mathrm{min}^{-1} \cdot \mathrm{kg}^{-1}\right)$ and predicted $\mathrm{VO}_{2 \text { Peak }}\left(19.9 \pm 4.3 \mathrm{ml} . \mathrm{min}^{-}\right.$

${ }^{1} \cdot \mathrm{kg}^{-1}$ ) was observed. DW multiplied by body mass (BM) was a significant predictor of $\mathrm{W}_{\text {Peak }}$ $(r=0.80)\left(\mathrm{W}_{\text {Peak }}(\mathrm{W})=[0.0018 \times(\mathrm{DW} \times \mathrm{BM})]+50.47\right)$. No difference $(p=0.97)$ between CPET $\left.W_{\text {Peak }} 116.2 \pm 38.9 \mathrm{~W}\right)$ and estimated $\mathrm{W}_{\text {Peak }}(113.9 \pm 30.1 \mathrm{~W})$ was seen.

77 Conclusions: The present study demonstrates that $\mathrm{VO}_{2 \text { Peak }}$ and $\mathrm{W}_{\text {Peak }}$ can be accurately estimated using the DW during an ISWT in CKD populations. 
87 Chronic kidney disease (CKD) is associated with reduced exercise capacity and increased cardiovascular disease risk (Go et al 2004). A growing body of research has shown that cardiorespiratory fitness, which can be reflected by peak oxygen consumption $\left(\mathrm{VO}_{2}\right.$ Peak $)$, is strongly related to a spectrum of health outcomes including cardiovascular disease and allcause mortality (Blair et al 1996, Harber et al 2017). In the general population, low cardiorespiratory fitness is a greater indicator of mortality than any other traditional risk factor (Blair 2009, Shah et al 2016, Laukkanen et al 2004, Myers et al 2002). A study of young adults aged 18-30 over a period of 26 years reporting a significant relationship between high cardiorespiratory fitness and reduced risk of all-cause mortality (Shah et al 2016). Further, in men aged 42-60 years, with and without conventional risk factors for cardiovascular disease, $\mathrm{VO}_{2 \text { Peak }}$ represented a strong predictor of fatal and non-fatal cardiac events (Laukkanen et al 2004), and Myers et al (2002) showed, in a sample of 6213 men, each 1-MET increase in exercise capacity, equating to $3.5 \mathrm{ml} \cdot \mathrm{min}^{-1} \cdot \mathrm{kg}^{-1}$, conferred a $12 \%$ improvement in survival.

Unsurprisingly, given its multi-morbid nature, CKD patients have was markedly reduced cardiorespiratory fitness compared to age-predicted values (Howden et al 2015). Such poor levels of cardiorespiratory fitness are associated with greater cardiovascular burden (e.g., aortic stiffness, poor left ventricular function), and overall elevated risk of further morbidity and mortality (Howden et al 2015, Gulati et al 2012, Mackinnon et al 2018). Whilst no estimate exists in patients not requiring renal replacement therapy, in end stage renal disease $\mathrm{VO}_{2}$ Peak

107 values $>17.5 \mathrm{ml} \cdot \mathrm{min}^{-1} \cdot \mathrm{kg}^{-1}$ are a powerful predictor of survival (Sietsema et al 2004).

108 Consequently, measuring cardiorespiratory fitness in CKD is fundamental for assessment of 109 current and prognostic health status and survival. 
111 Cardiorespiratory fitness (measured as $\mathrm{VO}_{2}$ Peak) represents the ability to utilise oxygen during

112 increased metabolic demand (Bassett and Howley 2000). The 'gold standard' assessment of

$113 \mathrm{VO}_{2 \text { Peak }}$ is through an incremental cardiopulmonary exercise test (CPET) (Palange et al 2007)

114 using breath-by breath sampling methods. However, these are poorly tolerated in older patients

115 with low fitness (Gill, DiPietro and Krumholz 2000), and require specialist costly equipment.

116 The incremental shuttle walk test (ISWT), a simple symptom-limited field test, has been used

117 as a surrogate marker of both $\mathrm{VO}_{2 \text { Peak }}$ and peak power output $\left(\mathrm{W}_{\text {Peak }}\right)$ in clinical populations

118 such as chronic obstructive pulmonary disease (COPD) (Singh et al 1994, Arnardottir et al

119 2006). Both $\mathrm{VO}_{2 \text { Peak }}$ and $\mathrm{W}_{\text {Peak }}$ can help set appropriate exercise intensities when prescribing

120 exercise, and our group have previously shown the ISWT and CPET to have good reliability

121 in CKD patients (Wilkinson et al 2018).

122

123 The aim of the present study was to develop prediction equations to estimate $\mathrm{VO}_{2 \text { Peak }}$ and $\mathrm{W}_{\text {Peak }}$

124 based on the distance walked (DW) during the ISWT. This can aid healthcare researchers and

125 professionals in the evaluation of patient health status, disease prognosis, and prescription of 126 appropriate exercise intensities for rehabilitation interventions without having to subject

127 patients to expensive and occasionally poorly tolerated laboratory testing. 


\section{Study design}

131 This is a secondary analysis of baseline data collected during an exercise trial 132 (\#ISRCTN36489137) which took place between December 2013 and October 2016. A full 133 description of the methods for this trial can be found in Watson et al (2018). The study was 134 approved by the National Research Ethics Committee, East Midlands-Northampton 135 (\#13/EM/0344) and all participants gave informed consent.

\section{Participants}

138 Patients were recruited from nephrology outpatient clinics and included if they had CKD stages $1393 b-5$, and were not yet requiring dialysis. Exclusion criteria were: a) aged $<18$ years; b) body mass index $(\mathrm{BMI})>40 \mathrm{~kg} / \mathrm{m}^{2}$; c) physical impairment preventing undertaking of the study assessments; d) myocardial infarction within $<6$ months; e) any unstable chronic condition

142 (e.g., diabetes); and f) inability to give informed consent.

144 Cardiopulmonary exercise testing

$145 \mathrm{VO}_{2 \text { Peak }}$ was determined using a symptom limited, graded, maximal effort CPET performed on 146 a cycle ergometer (Lode Excalibur, Groningen, The Netherlands). Participants underwent a full

147 test familiarisation. Following a 3-minute warm-up at a resistance of 50 watts (W), patients

148 were instructed to cycle $>60$ revolutions per minute (RPM). Work rate was increased using a 149 ramp protocol of incremental workloads of $1 \mathrm{~W} / 4$ seconds $(15 \mathrm{~W} / \mathrm{min})$ (Cortex Metasoft CPX 150 software, Leipzig, Germany). The test was stopped if the RPM dropped $<60$ or if the participant 151 reached volitional exhaustion. $\mathrm{VO}_{2 \text { Peak }}$ and $\mathrm{W}_{\text {Peak }}(\mathrm{W})$ were calculated over a rolling 20-second 152 average value. 
Incremental shuttle walk test

155 The ISWT involved participants walking up and down a 10 metre (m) course (Singh et al 1994, 156 Wilkinson et al 2018). Walking speed was controlled by an external auditory tone. The test

157 was maximal and progressive, with an initial speed of 0.5 metres per second $(\mathrm{m} / \mathrm{s})$, increasing 158 by $0.17 \mathrm{~m} / \mathrm{s}$ every minute, for a maximum of 12 minutes. Standardised instructions were played before each test. The test was terminated when the participant felt they were unable to continue or if the participant was unable to sustain the speed for two continuous shuttles. The DW throughout the test was calculated. All participants completed a prior familiarisation test.

\section{Statistical analysis}

As a CPET provides relative oxygen uptake (e.g., $\left.\mathrm{ml} \cdot \mathrm{min}^{-1} \cdot \mathrm{kg}^{-1}\right)$, we normalised ISWT results by systematically individually multiplying and then dividing the relative age, BMI, and body mass (BM) of the participants. These variables were selected as they are most likely to be available to healthcare professionals or researchers. Individual $r$ values were calculated for each variable by assessing the relationship between each variable and $\mathrm{VO}_{2 \text { Peak }}$ and $\mathrm{W}_{\text {Peak }}$ (see

Table 1). The variable with the highest $r$ value was used to develop the prediction equations for $\mathrm{VO}_{2 \text { Peak }}$ and $\mathrm{W}_{\text {Peak }}$.

171

172 Following selection of the most appropriate variable, linear regression was carried out: a)

173 between the DW (m) divided by BMI $\left(\mathrm{kg} / \mathrm{m}^{2}\right)$ and the $\mathrm{VO}_{2 \text { Peak }}\left(\mathrm{ml} \cdot \mathrm{min}^{-1} \cdot \mathrm{kg}^{-1}\right)$ determined using 174 CPET; and b) between the DW (m) multiplied by BM (kg) and the $\mathrm{W}_{\text {Peak }}(\mathrm{W})$ determined 175 during the CPET. This elicited adjusted prediction equations for $\mathrm{VO}_{2 \text { Peak }}$ and $\mathrm{W}_{\text {Peak }}$ adjusting 176 for BMI and BM respectively. To elicit unadjusted prediction equations for $\mathrm{VO}_{2}$ Peak and $\mathrm{W}_{\text {Peak }}$ 177 in conditions where BMI and BM measurements are absent, linear regression was also carried 
out: a) between DW and the $\mathrm{VO}_{2 \text { Peak }}\left(\mathrm{ml} \cdot \mathrm{min}^{-1} \cdot \mathrm{kg}^{-1}\right)$ determined using CPET; and b) between

179 the DW (m) and the $\mathrm{W}_{\text {Peak }}(\mathrm{W})$ determined during the CPET.

180

181 Non-normally distributed data underwent log transformation. Paired sample t-tests were used 182 to test for significant differences between values assessed using CPET and estimated $\mathrm{VO}_{2 \text { Peak }}$ 183 and $\mathrm{W}_{\text {Peak }}$ using the prediction equation. Paired sample t-tests were also used to test for 184 significant differences between estimated results using adjusted and unadjusted prediction 185 equations ( $\mathrm{VO}_{2 \text { Peak: }}$ adjusted for BMI; $\mathrm{W}_{\text {Peak: }}$ adjusted for $\left.\mathrm{BM}\right)$. Mean differences are shown 186 along with 95\% confidence intervals (95CI). Bland and Altman analysis plots assessed the 187 agreement between values obtained during CPET and estimated using the prediction equations. 188 Significance was set at $<0.050$. Data analysis was performed using IBM SPSS Statistics 24 189 (IBM, USA). 


\section{Results}

192

193 Out of the 54 patients consented to the main trial, 36 patients completed the CPET and the 194 ISWT. Baseline characteristics for these patients are found in Table 2.

195

196 Adjusted prediction equations

197

198

Prediction of $\mathrm{VO}_{2 \text { Peak }}$ using adjusted equations

199

Predicted $\mathrm{VO}_{2 \text { Peak }}$ determined using the DW adjusting for BMI revealed the following equation 200 $(r=0.78)($ Figure 1):

201

202

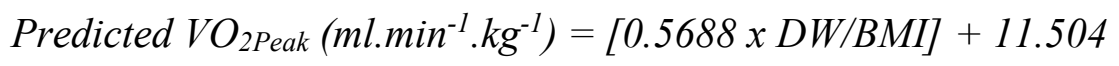

203

204

205

206 ml. $\left.\min ^{-1} \cdot \mathrm{kg}^{-1}\right)(p=0.66)$.

207

208

Prediction of $W_{\text {Peak }}$ using adjusted equations

209

The DW during the ISWT multiplied by body mass was a significant contributor to the 210 prediction of $\mathrm{W}_{\text {Peak }}(r=0.80)$ eliciting the following equation (Figure 1):

Predicted $W_{\text {Peak }}(W)=[0.0018 \times(D W \times B M)]+50.47$

214 Paired sample t-tests revealed no difference $(p=0.96)$ between $\mathrm{W}_{\text {Peak }}$ measured during CPET $215(116.2 \pm 38.9 \mathrm{~W})$ and estimated $\mathrm{W}_{\text {Peak }}$ using the prediction equation $(113.9 \pm 30.0 \mathrm{~W})(\mathrm{mean}$ 
216 difference: 2.3 (95CI -5.7 to 10.3) $\mathrm{W}_{\text {Peak }}$ ). Figure 1 illustrates Bland and Altman plots with

217 bias and limits of agreement at $95 \mathrm{CI}$, plotted for each method for obtaining $\mathrm{VO}_{2 \text { Peak }}$ and $\mathrm{W}_{\text {Peak }}$

218 using adjusted equations for either BMI or BM.

219

220 Unadjusted prediction equations

221

222

Prediction of $\mathrm{VO}_{2 \text { Peak }}$ using unadjusted equations

223 Predicted $\mathrm{VO}_{2 \text { Peak }}$ determined using the DW during the ISWT without adjusting for BMI 224 revealed the following equation $(r=0.74)$ (Figure 2):

225

226

Predicted $V_{2 P e a k}\left(\mathrm{ml} \mathrm{min}^{-1} \cdot \mathrm{kg}^{-1}\right)=[0.0216 \times \mathrm{DW}]+10.66$

227

228

Paired sample t-tests revealed no significant $(p=0.66)$ difference observed between $\mathrm{VO}_{2}$ Peak 229 measured by CPET $\left(19.9 \pm 5.5 \mathrm{ml} \cdot \mathrm{min}^{-1} \cdot \mathrm{kg}^{-1}\right)$ and estimated $\mathrm{VO}_{2 \text { Peak }}$ using the prediction 230 equation $\left(19.9 \pm 4.0 \mathrm{ml} \cdot \mathrm{min}^{-1} \cdot \mathrm{kg}^{-1}\right)\left(\right.$ mean difference: $0.0(95 \mathrm{CI}-1.2$ to 1.3$\left.) \mathrm{ml} \cdot \mathrm{min}^{-1} \cdot \mathrm{kg}^{-1}\right)$

231

232

Prediction of $W_{\text {Peak }}$ using unadjusted equations

233

Predicted $\mathrm{W}_{\text {Peak }}$ determined using the DW during the ISWT without adjusting for BW revealed 234 the following equation $(r=0.71)$.

235

236

Predicted $W_{\text {Peak }}(W)=[0.1465 \times D W(m)]+54.639$

237

238 Paired sample t-tests revealed no significant $(p=0.55)$ difference observed between $\mathrm{W}_{\text {Peak }}$ 239 measured during CPET $(116.2 \pm 38.9 \mathrm{~W})$ and estimated $\mathrm{VO}_{2 \text { Peak }}$ using the prediction equation $240(116.2 \pm 27.5 \mathrm{~W})$ (mean difference: 0.0 (95CI -9.5 to 9.4) $\mathrm{W}_{\text {Peak }}$ ). Figure 2 illustrates Bland 
241 and Altman plots with bias and limits of agreement at 95\% CI, plotted for each method for 242 obtaining $\mathrm{VO}_{2 \text { Peak }}$ and $\mathrm{W}_{\text {Peak }}$ using unadjusted equations for either BMI or BM.

243 
Discussion

245

246 CPET is considered the 'gold standard' for measuring aerobic capacity, an important risk factor 247 determining morbidity and mortality in CKD (Howden et al 2015, Gulati et al 2012). This is 248 demonstrated by Gulati et al. (2012) who reported that $\mathrm{VO}_{2 \text { Peak }}$ values $<17.5 \mathrm{ml} \cdot \mathrm{min}^{-1} \cdot \mathrm{kg}^{-1}(\sim 5$ 249 MET's) combined with estimated glomerular filtration rate values of $<45 \mathrm{ml} \cdot \mathrm{min}^{-1} .1 .73 \mathrm{~m}^{2}$ were 250 associated with higher mortality rates compared to those with better aerobic capacity and eGFR. In the present study, we report an average of $\mathrm{VO}_{2 \text { Peak }}$ of $19.9 \mathrm{ml} \cdot \mathrm{min}^{-1} \cdot \mathrm{kg}^{-1}$ determined using CPET; these values are below that of comparative age-matched healthy sedentary individuals (Herdy and Uhlendorf 2011).

We found the relationship $(r=0.78)$ between DW during an ISWT and $\mathrm{VO}_{2 \text { Peak }}$ obtained during CPET support the findings of others in COPD $(r=0.72(20), r=0.88$ (Singh et al 1994, Onorati et al 2003). Similar relationships $(r=0.74)$ have also been reported in idiopathic pulmonary fibrosis (Moloney et al 2003), and heart failure $(r=0.83)$ (Green et al 2001). It has been shown that $\mathrm{VO}_{2 \text { Peak }}$ determined using a treadmill based CPET is higher than $\mathrm{VO}_{2}$ Peak values measured using a cycle based CPET (Myers et al 2009, Christensen et al 2004), thus a regression equation derived using a non-cycle walking based test could be expected to overestimate $\mathrm{VO}_{2}$ Peak determined using an incremental cycle CPET. However, in the present study, average $\mathrm{VO}_{2 \text { Peak }}$ values determined during CPET $\left(19.9 \pm 5.5 \mathrm{ml} \cdot \mathrm{min}^{-1} \cdot \mathrm{kg}^{-1}\right)$ were almost identical to estimated

$264 \mathrm{VO}_{2 \text { Peak }}$ values determined using both formulas adjusted $\left(19.9 \pm 4.3 \mathrm{ml} \cdot \mathrm{min}^{-1} \cdot \mathrm{kg}^{-1}\right)$ and unadjusted $\left(19.9 \pm 4.0 \mathrm{ml} \cdot \mathrm{min}^{-1} \cdot \mathrm{kg}^{-1}\right)$ for BMI.

267 We also used the DW during the ISWT to develop a prediction equation of $\mathrm{W}_{\text {Peak. }}$ The 268 relationship $(r=0.80)$ we observed between $\mathrm{W}_{\text {Peak }}$ obtained during CPET and estimated using 
292 Arnardottir et al (2006) discussed the possibility that the prediction equations they provided 293

the prediction equation adjusted for BM supports research by Arnardottir et al (2006), who also showed a strong relationship $(r=0.88)$ between DW during the ISWT after controlling for body mass and $\mathrm{W}_{\text {Peak }}$ obtained during CPET in 93 COPD patients. Given the high prevalence of cardiovascular disease in CKD populations, many patients are prescribed $\beta$-blockers to manage hypertension. The confounding effects of this medication makes it difficult to prescribe exercise intensities according to heart rate target zones in this patient population. Therefore, the prediction equation in our study estimating $\mathrm{W}_{\text {Peak }}$ through DW during the ISWT may be more useful than the use of peak heart rate for the prescription of exercise in this patient population. Further, patients whom use a cycle ergometer in the gym or at home, and without knowledge of their heart rate, could set appropriate exercise intensities using $\mathrm{W}_{\text {Peak }}$.

No significant differences were seen between data obtained using adjusted and unadjusted equations for $\mathrm{VO}_{2 \text { Peak }}$ and $\mathrm{W}_{\text {Peak }}(p=0.93 ; p=0.14$, respectively). This suggests that in the absence of BM or BMI measurements, the unadjusted equations still provide a valid means of estimating $\mathrm{VO}_{2 \text { Peak }}$ and $\mathrm{W}_{\text {Peak }}$. Being able to measure $\mathrm{VO}_{2 \text { Peak }}$ and $\mathrm{W}_{\text {Peak }}$ using the ISWT does not make the ISWT a perfect substitute for the laboratory based incremental cycle test or other forms of laboratory based CPET. In the present study, slight variations were seen between estimated and measured peak values on an individual basis (as seen in the Bland and Altman plots with measures falling outside the $95 \% \mathrm{CI}$ ) however, when grouped, values showed no significant difference, making the ISWT together with our prediction equations a valid means of obtaining this data in the absence of expensive laboratory tests or when these tests are poorly tolerated by the patients.

for COPD could be inversed, making it possible to calculate walking speed from $\mathrm{W}_{\text {Peak }}$ 
294 determined during CPET. This is also possible with the equations presented in the present study. Given that the equations work both ways, it is possible to estimate the DW during an ISWT and therefore, walking speed from $\mathrm{W}_{\text {Peak }}$ determined during CPET. This may be useful in clinics that have laboratory based cycle testing as routine practice but want to prescribe walking based exercise instead of gym or home based exercise.

\section{Study limitations}

301 The patient population in the present study was an opportunistic sample obtained from a randomised clinical trial carried out by our group, and therefore the findings are limited by the characteristics of the cohort included. For example, the prediction equations may not be applicable to CKD patients outside the eGFR, BMI or age range studied. A larger and more diverse population would be required to tailor prediction equations for possible confounding factors such as BMI, gender, and ethnicity. Additionally, the present method of estimating $\mathrm{VO}_{2 \text { Peak }}$ is only limited to people that can effectively carry out the walking test. Balance issues or visual impairments may influence the correct application of the walking test thus affecting predicted $\mathrm{VO}_{2}$ Peak values. Another possible limitation is our use of a cycle ergometer for the

310 CPET, whereas a treadmill test may have provided a more relevant comparison to the ISWT. Indeed, previous studies have shown higher rates of $\mathrm{O} 2$ consumption and $\mathrm{CO} 2$ production in peak tests using a treadmill than a cycle protocol (Muscat et al 2015), although other exercise

313 parameters did not differ between the two protocols. In this study, we chose to use the

314 ergometer for patients safety reasons and because it is easier to standardise than a treadmill test and therefore likely provides more reproducible results, Furthermore, many patient participants are unfamiliar with exercise equipment and feel more confident to exert themselves seated on an ergometer than walking or running on a treadmill. 
319 Implications for clinical practice

320 Cardiorespiratory fitness is a strong predictor of outcome and an important measure of health

321 status in the general population and in chronic disease states, including CKD. CPET is the gold322 standard method for measuring it but requires specialist equipment and a trained operator and

323 is therefore costly and often inaccessible for general use by renal clinicians, nurses and other

324 allied healthcare staff. In the present study, we have identified that the ISWT is a good predictor 325 of cardiorespiratory fitness in non-dialysis CKD. We have developed adjusted and unadjusted

326 formulae that use the DW during an ISWT and measures of BMI and BM to predict both

$327 \mathrm{VO}_{2 \text { Peak }}$ and $\mathrm{W}_{\text {Peak. }}$ This is of clinical importance as the ISWT is a considerably cost-effective 328 and simpler method for estimating aerobic capacity. These formulae provide a simple means

329 to estimate both $\mathrm{VO}_{2}$ Peak and $\mathrm{W}_{\text {Peak }}$ in non-dialysis CKD patients, which can be easily used as 330 a field test by the renal multidisciplinary team.

\section{Conclusions}

333 The present study demonstrates that peak aerobic capacity and peak exercise capacity can be 334 estimated using an ISWT with similar accuracy as CPET in non-dialysis CKD populations staged $3 b-5$. Early measures of cardiorespiratory and exercise capacity represent a quantifiable and prognostic biomarker of survival in this patient population. Therefore, the ability to evaluate and monitor improvements in peak aerobic capacity easily, coupled with the ability to

338 set appropriate exercise intensities using $W_{\text {Peak }}$ without the use of expensive equipment can 339 provide a means to evaluate and improve the risk of adverse events. 


\section{References}

342

343 Go AS, Chertow GM, Fan D et al (2004) Chronic kidney disease and the risks of death,

344 cardiovascular events, and hospitalization. $N$ Engl J Med 351(13),1296-1305

345 Blair SN, Kampert JB, Kohl HW et al (1996) Influences of cardiorespiratory fitness and other

346 precursors on cardiovascular disease and all-cause mortality in men and women. JAMA 276(3),

$347 \quad 205-210$

348 Harber MP, Kaminsky LA., Arena R et al (2017) Impact of cardiorespiratory fitness on all349 cause and disease-specific mortality: advances since 2009. Prog Cardiovasc Dis 60(1),11-20

350 Blair SN. (2009) Physical inactivity: the biggest public health problem of the $21^{\text {st }}$ century. $\mathrm{Br}$

$351 \quad J$ Sports Med 43(1),1-2

352 Shah RV, Murthy VL, Colangelo LA et al (2016). Association of fitness in young adulthood

353 with survival and cardiovascular risk: The Coronary Artery Risk Development in Young 354 Adults (CARDIA) Study. JAMA Int Med 176(1), 87-95

355 Laukkanen JA, Kurl S, Salonen R et al (2004). The predictive value of cardiorespiratory fitness

356 for cardiovascular events in men with various risk profiles: a prospective population-based 357 cohort study. Eur Heart J 25,1428-1437

358 Myers J, Prakash M, Froelicher V et al (2002). Exercise capacity and mortality among men 359 referred for exercise testing. $N$ Engl J Med 346(11),793-801

360 Howden EJ, Weston K, Leano R et al (2015) Cardiorespiratory fitness and cardiovascular

361 burden in chronic kidney disease. J Sci Med Sport 18(4),492-497

362 Gulati M, Black HR, Arnsdorf MF et al (2012). Kidney dysfunction, cardiorespiratory fitness, 363 and the risk of death in women. J Womens Health 21,917-924 
MacKinnon HJ, Wilkinson TJ, Clarke AL et al (2018). The association of physical function

365

366

367

368

369

370

371

372

373

374

375

376

377

378

379

380

381

382

383

384

385

386 and physical activity with all-cause mortality and adverse clinical outcomes in non-dialysis chronic kidney disease: a systematic review. Ther Adv Chronic Dis 9(11),209-226

Muscat KM, Kotrach HG, Wilkinson-Maitland CA et al (2015). Physiological and perceptual responses to incremental exercise testing in healthy men: effect of exercise test modality. Appl Physiol Nutr Metab 40(11):1199-209

Sietsema KE, Amato A, Adler SG et al (2004). Exercise capacity as a predictor of survival among ambulatory patients with end-stage renal disease. Kidney Int 65,719-724

Bassett Jr DR, Howley ET (2000). Limiting factors for maximum oxygen uptake and determinants of endurance performance. Med Sci Sports Exerc 32(1),70-84

Palange P, Ward SA, Carlsen KH, et al (2007). Recommendations on the use of exercise testing in clinical practice. Eur Respir J 29,185-209

Gill TM, DiPietro L, Krumholz, HM (2000). Role of exercise stress testing and safety monitoring for older persons starting an exercise program. Jama 284(3),342-349

Singh SJ, Morgan MD, Hardman AE et al (1994). Comparison of oxygen uptake during a conventional treadmill test and the shuttle walking test in chronic airflow limitation. Eur Res $J$ 7(11),2016-2020

Arnardóttir RH, Emtner M, Hedenström H et al (2006). Peak exercise capacity estimated from incremental shuttle walking test in patients with COPD: a methodological study. Respir Res $7(1), 127$

Wilkinson TJ, Xenophontos S, Gould DW et al (2018) Test-retest reliability, validation, and "minimal detectable change" scores for frequently reported tests of objective physical function in patients with non-dialysis chronic kidney disease. Physiother Theory Pract 30,1-12 
387 Watson EL, Gould DW, Wilkinson TJ et al (2018) 12-weeks combined resistance and aerobic 388 training confers greater benefits than aerobic alone in non-dialysis CKD. Am J Physiol Renal 389 Physiol 4(6), 1188-1196

390 Herdy AH, Uhlendorf D. (2011) Reference Values for Cardiopulmonary Exercise Testing for 391 Sedentary and Active Men and Women. Arq Bras Cardiol 96(1): 54-59

392 Onorati P, Antonucci R, Valli G et al (2003). Non-invasive evaluation of gas exchange during 393 a shuttle walking test vs. a 6-min walking test to assess exercise tolerance in COPD patients. 394 Eur J Appl Phys 89,331-336

395 Moloney E, Clayton N, Mukherjee D et al (2003). The shuttle walk exercise test in idiopathic 396 pulmonary fibrosis. Resp Med 97(6),682-687

397 Green DJ, Watts K, Rankin S et al (2001). A comparison of the shuttle and 6 minute walking 398 tests with measured peak oxygen consumption in patients with heart failure. J Sci Med Sport $3994(3), 292-300$

400 Myers J, Arena R, Franklin B et al (2009) Recommendations for clinical exercise laboratories: 401 a scientific statement from the American Heart Association. Circulation 119(24),3144-3161

402 Christensen C, Ryg M, Edvardsen A et al (2004). Effect of exercise mode on oxygen uptake 403 and blood gases in COPD patients. Resp Med 98(7),656-660 
405 Table 1. Relationship between CPET values with adjusted and unadjusted ISWT values

\begin{tabular}{lll}
\hline & VO $_{2 \text { Peak }}(r)$ & Weak \\
\hline DW x Age & 0.52 & 0.55 \\
DW x BMI & 0.57 & 0.72 \\
DW x BM & 0.64 & $\mathbf{0 . 8 0}$ \\
DW / Age & 0.52 & 0.61 \\
DW / BMI & $\mathbf{0 . 7 8}{ }^{\S}$ & 0.59 \\
DW / BM & 0.73 & 0.48 \\
DW & 0.74 & 0.71 \\
\hline
\end{tabular}

406

407 DW, distance walked during an incremental shuttle walk test; BMI, body mass index; BM, 408 body mass; ${ }^{\S}$ variable used to create the prediction equation for estimating $\mathrm{VO}_{2 \text { Peak }}$; variable 409 used to create the prediction equation for estimating $\mathrm{W}_{\text {Peak }}$

410 
411 Table 2. Patient characteristics

$n=36$

\begin{tabular}{|c|c|}
\hline Age (years) & $61 \pm 12$ \\
\hline eGFR (ml.min $\left.{ }^{-1} \cdot 1.73 \mathrm{~m}^{2}\right)$ & $25 \pm 7$ \\
\hline Number of males & 17 \\
\hline \multicolumn{2}{|l|}{ Ethnicity } \\
\hline White & 25 \\
\hline Indian/South Asian & 9 \\
\hline Black Caribbean & 2 \\
\hline Body mass index $\left(\mathrm{kg} / \mathrm{m}^{2}\right)$ & $31 \pm 6$ \\
\hline Systolic/diastolic blood pressure $(\mathrm{mmHg})$ & $137 \pm 13 / 80 \pm 9$ \\
\hline $\mathrm{VO}_{2 \text { Peak }}\left(\mathrm{ml} \cdot \mathrm{min}^{-1} \cdot \mathrm{kg}^{-1}\right)$ & $19.9 \pm 5.5$ \\
\hline ISWT distance walked (m) & $430 \pm 190$ \\
\hline Haemoglobin $(g / d L)$ & $119 \pm 15$ \\
\hline \multicolumn{2}{|l|}{ Comorbid conditions } \\
\hline Diabetes, $n(\%)$ & $9(25)$ \\
\hline Hypertension, $n(\%)$ & $15(42)$ \\
\hline
\end{tabular}

412

413 Abbreviations: eGFR, estimated glomerular filtration rate; ISWT, incremental shuttle walk test 414 
A)

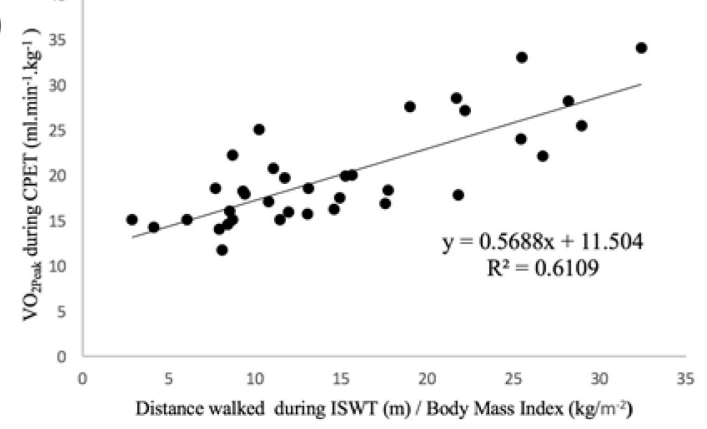

C)

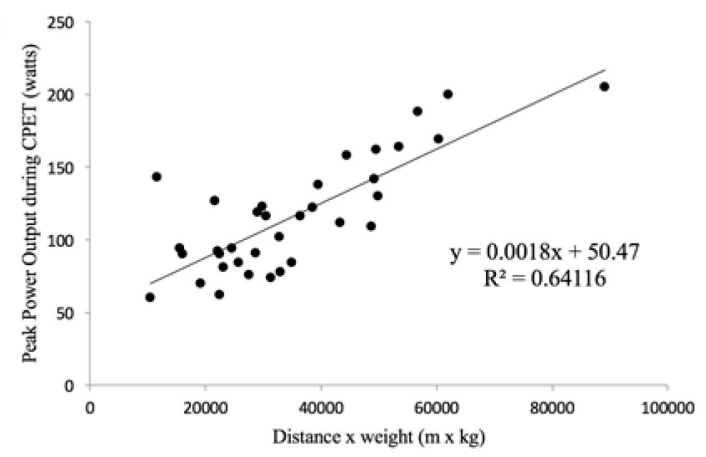

B)

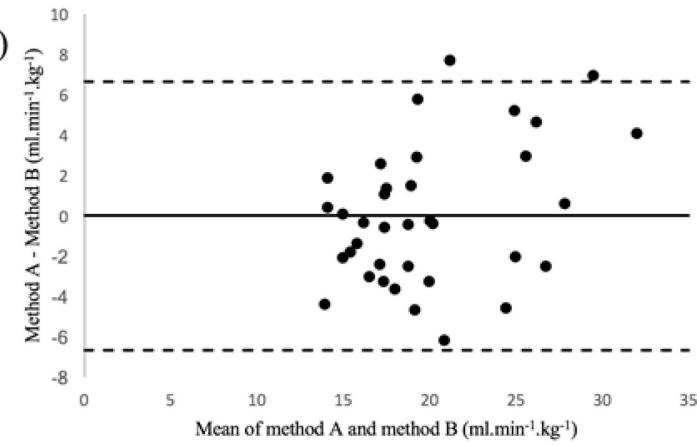

D)

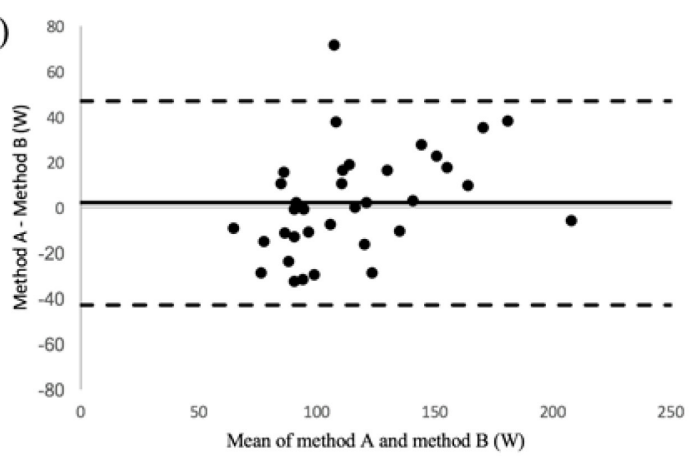

416 Figure 1.

417 (1A) the correlation between $\mathrm{VO}_{2 \text { Peak }}$ measured during a cardiopulmonary exercise test (CPET) 418 and the distance walked during an incremental shuttle walking test (ISWT) divided by body 419 mass index (BMI);

420 (1B) a Bland and Altman scatterplot comparing $\mathrm{VO}_{2 \text { Peak }}$ values obtained during CPET and 421 estimated using the prediction equation;

422 (1C) the correlation between $\mathrm{W}_{\text {Peak }}(\mathrm{W})$ measured during CPET and the distance walked during 423 the ISWT multiplied by body mass;

424 (1D) a Bland and Altman scatterplot comparing $\mathrm{W}_{\text {Peak }}$ values obtained during CPET and 425 estimated using the prediction equation 
A)

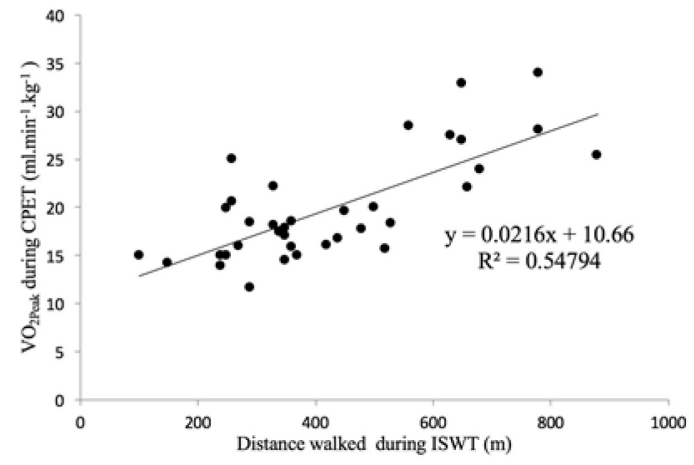

C)

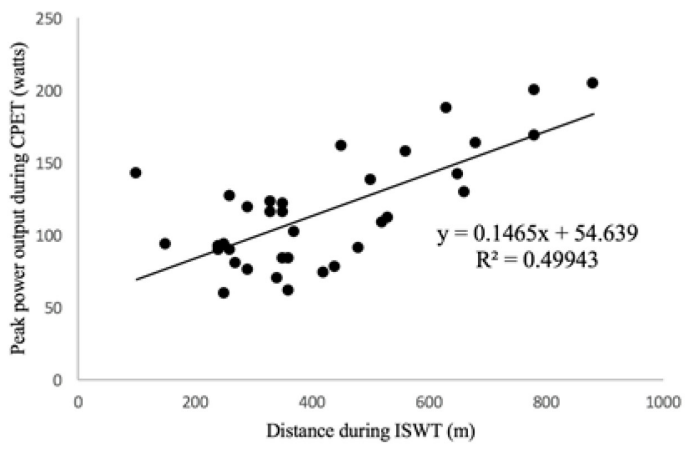

B)

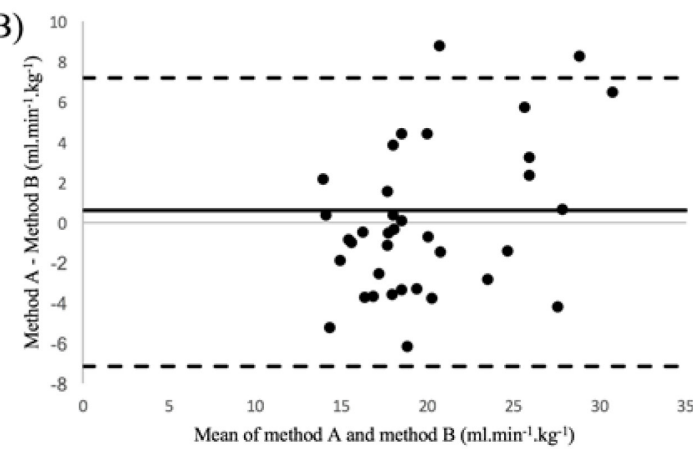

D)

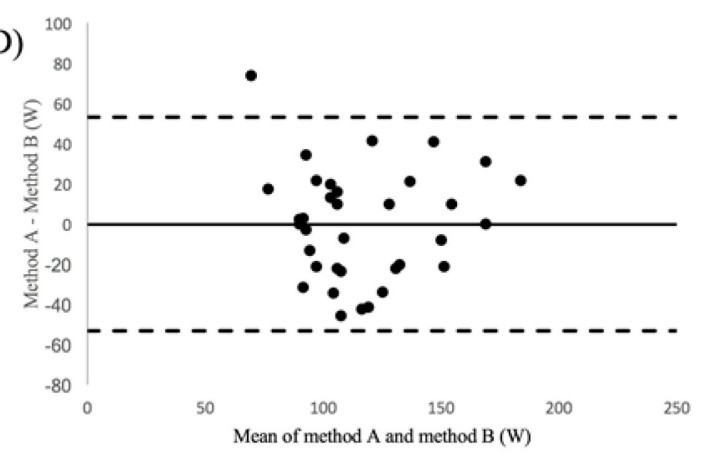

Figure 2.

$430(2 \mathrm{~A})$ the correlation between $\mathrm{VO}_{2 \text { Peak }}$ measured during a cardiopulmonary exercise test (CPET)

431 and the distance walked during an incremental shuttle walking test (ISWT);

432 (2B) a Bland and Altman scatterplot comparing $\mathrm{VO}_{2}$ Peak values obtained during CPET and

433 estimated using the prediction equation;

434 (2C) the correlation between $\mathrm{W}_{\text {Peak }}$ measured during CPET and the distance walked during an 435 incremental shuttle walking test (ISWT);

436 (2D) a Bland and Altman scatterplot comparing $\mathrm{W}_{\text {Peak }}$ values obtained during CPET and 437 estimated using the prediction equation 